\title{
NOTE \\ Surgery \\ Comparison of plasma propofol concentration for apnea, response to mechanical ventilation, and airway device between endotracheal tube and supraglottic airway device in Beagles
}

\author{
Tomoya IIZUKA ${ }^{1)}$, Kenichi MASUI')*, Hideko KANAZAWA ${ }^{3)}$ and \\ Ryohei NISHIMURA ${ }^{1)}$ \\ 1) Laboratory of Veterinary Surgery, Graduate School of Agricultural and Life Sciences, The University of Tokyo, \\ 1-1-1 Yayoi, Bunkyo-ku, Tokyo 113-8657, Japan \\ ${ }^{2)}$ Department of Anesthesiology, Showa University School of Medicine, 1-5-8 Hatanodai, Shinagawa-ku, \\ Tokyo 142-8666, Japan \\ 3) Faculty of Pharmacy, Keio University, 1-5-30 Shibakoen, Minato-ku, Tokyo 105-8512, Japan
}

J. Vet. Med. Sci.

80(9): 1420-1423, 2018

doi: 10.1292/jvms.17-0468

Received: 20 August 2017

Accepted: 8 July 2018

Published online in J-STAGE: 17 July 2018

\begin{abstract}
The relationships between propofol plasma concentrations and the pharmacodynamic endpoints may differ according to a type of airway device. To clarify these relationships in different airway devices would be useful to avoid the complication such as apnea and intraoperative awareness. The aim of this study was to investigate the influence of difference of airway device on propofol requirement during maintenance of anesthesia in dogs. We compared the influence of airway devices on the plasma propofol concentrations for apnea, response to mechanical ventilation, and response to airway device between endotracheal tube (ETT) and supraglottic airway device (SGAD) in Beagles. The pharmacodynamic effects were repeatedly assessed at varying propofol concentrations. The plasma concentrations (mean \pm SD) of propofol in the ETT and SGAD groups were $10.2 \pm 1.8$ and $10.9 \pm 2.4 \mu \mathrm{g} / \mathrm{m} /$ for apnea $(P=0.438), 7.9 \pm 1.2$ and $7.4 \pm 1.5 \mu \mathrm{g} / \mathrm{m} /$ for response to mechanical ventilation $(P=0.268)$, and 5.2 \pm 0.7 and $5.4 \pm 1.5 \mu \mathrm{g} / \mathrm{m} /$ for response to airway device $(P=0.580)$, respectively. Required propofol concentration during maintenance of anesthesia may be similar between ETT and SGAD. Without moderate to strong stimuli such as airway device insertion or painful stimulation during surgery, the type of airway device may have little impact on required propofol concentration during maintenance of anesthesia in dogs.
\end{abstract}

KEY WORDS: dog, endotracheal tube, propofol, supraglottic airway device

Endotracheal intubation is generally used for airway management during general anesthesia to secure airway patency [13]. Nowadays, supraglottic airway device (SGAD) such as laryngeal mask airway is also used in animals. Several studies have reported that a SGAD was able to use for dogs as an alternative to the endotracheal tube (ETT) [15, 20, 21].

Anesthetic requirements depend on not only pharmacodynamic endpoints but also other factors such as coadministration of opioid [8], gender [11], age [14], and airway device [21]. A previous study revealed that airway device influenced anesthetic requirements during an insertion of the airway device, SGAD required less propofol than ETT in dogs [21]. Based on the result of this study, some anesthesiologists reduce propofol dose not only for airway device insertion but also during maintenance of anesthesia. However, requirements of volatile agent were similar between ETT and SGAD during maintenance of anesthesia in human [9]. In dogs, influence of airway device on anesthetic requirements had been unclear during maintenance of anesthesia and also at removal of airway device. If the propofol requirement is not influenced by the type of airway device during maintenance of anesthesia, reduction of propofol dose may cause insufficient anesthesia. Therefore, the influence of airway device on anesthetic requirements should be clarified for safety in anesthetized animals.

Pharmacodynamic endpoints including apnea, response to mechanical ventilation, and response to airway device are important for anesthesia practice. Apnea may result in hypoxia, which can occur during induction of anesthesia [4]. Response to mechanical ventilation such as the patient-ventilator dyssynchrony may result in arrhythmia and hypotension [16]. Response to airway device 
such as chewing the airway device and lifting of the head should be avoided during anesthesia because this may cause accidental removal of the airway device. As the pharmacodynamic effect is related to the plasma concentration (Cp) [6], to elucidate the required Cps to achieve the pharmacodynamic effects are useful to control anesthetic agents at appropriate level.

The relationships between propofol Cps and the pharmacodynamic endpoints including apnea, response to mechanical ventilation, and response to airway device have been investigated using endotracheal tube [8]. However, a different airway device may influence these pharmacodynamic relationships because SGAD decrease the propofol requirement for its insertion compared to endotracheal tube [21]. As propofol is often used for induction and maintenance of anesthesia in animals due to its advantage over the inhalation anesthetics including smooth recovery and stable hemodynamic function $[1,7,10,17]$, to clarify these relationships would be useful to avoid the complications such as apnea and intraoperative awareness. The aim of the present study was to elucidate the requirement of propofol $\mathrm{Cp}$ for apnea, response to mechanical ventilation, and response to airway device, and compare these Cps between the ETT and SGAD.

This study was approved by the Animal Care and Use Committee of the Graduate School of Agricultural and Life Sciences, the University of Tokyo, and followed the guidelines for the care and use of laboratory animals in the institution. Three male and three female healthy Beagles were used in the study. The mean $\pm \mathrm{SD}$ of age and body weight were $1.6 \pm 0.1$ years and $11.0 \pm 1.1 \mathrm{~kg}$, respectively. All dogs were anesthetized using the ETT or SGAD for airway management in a randomized cross-over design with more than one-week intervals.

The dogs were fasted for $12 \mathrm{hr}$ prior to the experiment with free access to water. Anesthesia was induced and maintained with propofol. After the anesthesia was induced and lack of jaw tone, loss of swallowing, and lack of head shaking were achieved, the airway was secured using one of the following devices: ETT group, a 7.5-mm inner diameter ETT (Sheridan endotracheal tube, Intermed Japan, Osaka, Japan); SGAD group, a size 2.5 SGAD (Tokibo-Ambu laryngeal mask, Tokibo, Tokyo, Japan). The cuff of the ETT or SGAD was inflated to avoid cuff leak after the insertion of the device. Immediately after the application of the airway device, mechanical ventilation was started using a ventilator (Mini Vent-3 animal; Cross Medical Service, Tokyo, Japan) with $100 \%$ oxygen $(1 \mathrm{l} / \mathrm{min})$ in a semi-closed circuit. Synchronized intermittent mandatory ventilation at the fixed respiratory rate $\left(12\right.$ breaths $/ \mathrm{min}$ ) was performed. The tidal volume was adjusted to maintain the end-tidal carbon dioxide tension $\left(\mathrm{EtCO}_{2}\right)$ at approximately $40 \mathrm{mmHg}$ during mechanical ventilation. A 24-gauge, 19-mm over-the-needle catheter was inserted into the dorsal pedal artery for blood pressure monitoring and blood sampling. Heart rate, mean arterial pressure, peripheral oxygen saturation, respiratory rate, and $\mathrm{EtCO}_{2}$ were recorded throughout the study. Arterial carbon dioxide tension $\left(\mathrm{PaCO}_{2}\right)$ was measured at the first pharmacodynamic assessment and at the removal of airway device. The mechanical ventilation was terminated when the dog appeared to be fighting the ventilator (patient-ventilator dyssynchrony). Anesthesia was then maintained under spontaneous ventilation.

Dosing schemes of propofol were determined using pharmacokinetic simulation as previously reported [8]. In brief, the simulation using the pharmacokinetic parameter of propofol [2] allows us to determine bolus doses and infusion rates to maintain a constant drug concentration. Based on the real-time pharmacokinetic simulation, propofol infusion was started and the infusion rate was adjusted to maintain the predicted propofol $\mathrm{Cp}$ at $10 \mu \mathrm{g} / \mathrm{m} l$ until first assessment of clinical response. After the first assessment, the predicted propofol Cp was decreased by a step of $1 \mu \mathrm{g} / \mathrm{m} l$ every $20 \mathrm{~min}$, and the pharmacodynamic assessment was repeated until the dog responded to airway device (Fig. 1). During the final 5 min of each Cp step of propofol, blood sampling and the pharmacodynamic assessment were performed as the following order: (1) the first blood sampling; (2) assessment of pharmacodynamic effects of propofol for apnea, response to mechanical ventilation, and response to airway device; (3) the second blood sampling (Fig. 1). When the dog responded to the airway device, we removed the airway device and draw a blood sample. The $4 \mathrm{ml}$ arterial blood was drawn at each sampling, the plasma was separated from the collected sample by centrifugation, and measured propofol $\mathrm{Cp}$ was determined as previously reported [8]. 'Apnea' was defined as the absence of spontaneous ventilation for longer than $30 \mathrm{sec}$ after temporary disconnection from the respiratory circuit and mechanical ventilator. Once the dogs breathed spontaneously, we omitted further assessment of the apnea in the following Cp steps. 'Response to mechanical ventilation' was defined as the dog patient-ventilator dyssynchrony, i.e. a cough reflex of the dog was observed regardless of the spontaneous ventilation. Once the dogs responded to mechanical ventilation, the mechanical ventilation was terminated and further assessment was omitted. 'Response to airway device' was defined as the dog chewing the airway device or lifting of the head [5].

Heart rate, mean arterial pressure, peripheral oxygen saturation, respiratory rate, $\mathrm{EtCO}_{2}$, and $\mathrm{PaCO}_{2}$ at the first pharmacodynamic assessment and at the airway device removal, and propofol $\mathrm{Cp}$ for the each pharmacodynamic endpoint between groups were compared using paired $t$-test. Propofol $\mathrm{Cp}$ for apnea or response to mechanical ventilation in each dog was estimated using measured $\mathrm{Cps}$ by probit analysis. Propofol $\mathrm{Cp}$ for response to airway device in each dog was determined as the measured $\mathrm{Cp}$ when the dog responded to the device. A $P$ value $<0.05$ was regarded as significant. Statistical analyses were done using $\mathrm{R} 3.3 .2$ (http:// www.R-project.org).

The cardiopulmonary parameters are listed in Table 1 . There were no significant differences in the heart rate, mean arterial pressure, peripheral oxygen saturation, respiratory rate, and $\mathrm{EtCO}_{2}$. The $\mathrm{PaCO}_{2}$ in the ETT group at the airway device removal was significantly lower than that in the SGAD group $(P=0.023)$.

The propofol $\mathrm{Cp}$ in the ETT group and SGAD group were $10.2 \pm 1.8$ and $10.9 \pm 2.4 \mu \mathrm{g} / \mathrm{m} l$ for apnea $(P=0.438), 7.9 \pm 1.2$ and $7.4 \pm 1.5 \mu \mathrm{g} / \mathrm{m} l$ for response to mechanical ventilation $(P=0.268)$, and $5.2 \pm 0.7$ and $5.4 \pm 1.5 \mu \mathrm{g} / \mathrm{m} l$ for response to airway device $(P=0.580)$, respectively.

Impact of the airway device type was small on the pharmacodynamic effects of propofol for apnea, response to mechanical ventilation, and response to airway device. A previous study has reported that SGAD needed less propofol for insertion of 

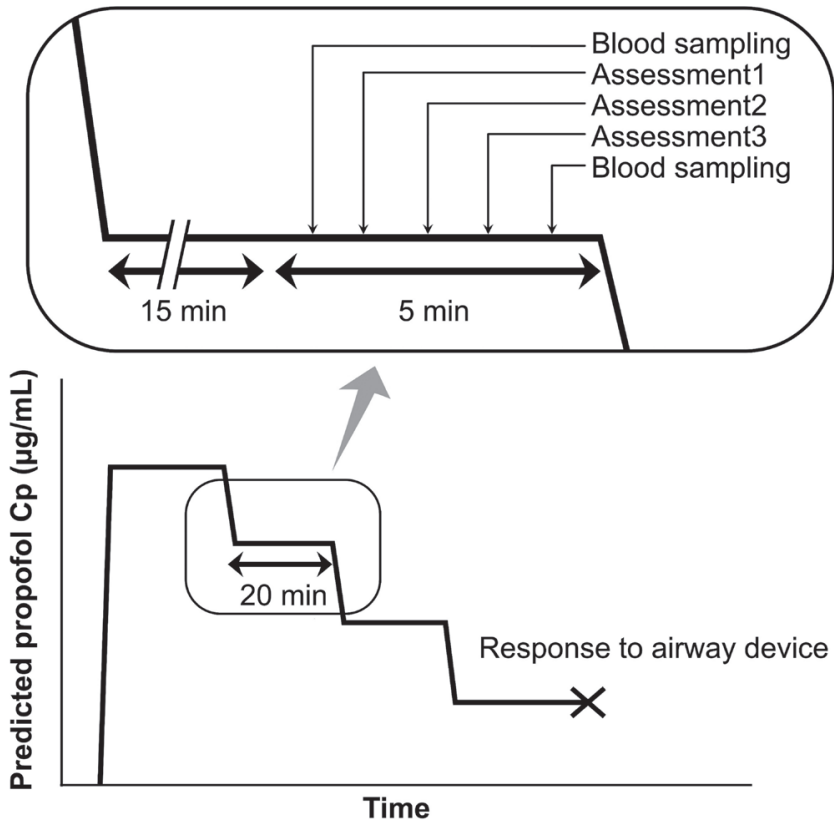

Fig. 1. Time course of propofol plasma concentration (Cp), and sequence of blood sampling and pharmacodynamic assessments. During the final 5 min of the each Cp step of propofol, we performed the blood sampling and series of assessment of clinical responses. In a sequence of the series of pharmacodynamic assessments, apnea was assessed (Assessment 1), then responses to mechanical ventilation (Assessment 2), and response to airway device was assessed lastly (Assessment 3). The predicted propofol $\mathrm{Cp}$ was decreased by a step of $1 \mu \mathrm{g} / \mathrm{m} l$ every $20 \mathrm{~min}$, and the pharmacodynamic assessment was repeated until the dog exhibited response to airway device.
Table 1. Hemodynamic and respiratory variables in 6 dogs

\begin{tabular}{|c|c|c|c|}
\hline & ETT & SGAD & $P$ value \\
\hline \multicolumn{4}{|c|}{ HR (beats/min) } \\
\hline $\mathrm{T} 1$ & $89 \pm 12$ & $97 \pm 29$ & 0.576 \\
\hline $\mathrm{T} 2$ & $134 \pm 27$ & $142 \pm 24$ & 0.591 \\
\hline \multicolumn{4}{|c|}{ MAP (mmHg) } \\
\hline $\mathrm{T} 1$ & $80 \pm 14$ & $79 \pm 7$ & 0.822 \\
\hline $\mathrm{T} 2$ & $96 \pm 14$ & $98 \pm 18$ & 0.795 \\
\hline \multicolumn{4}{|c|}{$\mathrm{SpO}_{2}(\%)$} \\
\hline $\mathrm{T} 1$ & $98 \pm 1$ & $97 \pm 1$ & 0.135 \\
\hline $\mathrm{T} 2$ & $98 \pm 3$ & $98 \pm 1$ & 0.771 \\
\hline \multicolumn{4}{|c|}{ Respiratory rate (breaths/min) } \\
\hline $\mathrm{T} 1$ & $12 \pm 0$ & $12 \pm 0$ & NA \\
\hline $\mathrm{T} 2$ & $78 \pm 65$ & $73 \pm 30$ & 0.856 \\
\hline \multicolumn{4}{|c|}{$\mathrm{EtCO}_{2}(\mathrm{mmHg})$} \\
\hline $\mathrm{T} 1$ & $40 \pm 1$ & $40 \pm 1$ & $>0.999$ \\
\hline $\mathrm{T} 2$ & $30 \pm 4$ & $37 \pm 8$ & 0.156 \\
\hline \multicolumn{4}{|c|}{$\mathrm{PaCO}_{2}(\mathrm{mmHg})$} \\
\hline $\mathrm{T} 1$ & $44 \pm 2$ & $46 \pm 3$ & 0.361 \\
\hline $\mathrm{T} 2$ & $34 \pm 6$ & $41 \pm 3$ & 0.023 \\
\hline
\end{tabular}

Mean \pm standard deviation. ETT: endotracheal tube, SGAD: supraglottic airway device, HR: heart rate, MAP: mean arterial pressure, $\mathrm{SpO}_{2}$ : peripheral oxygen saturation, $\mathrm{EtCO}_{2}$ : end-tidal carbon dioxide tension, $\mathrm{PaCO}_{2}$ : arterial carbon dioxide tension, $\mathrm{T} 1$ : the time at the first pharmacodynamic assessment, T2: the time at airway device removal, NA: not applicable.

the airway device compared to ETT in dogs [21]. In contrast, the other study resulted that a dose of propofol was comparable between ETT and SGAD for anesthesia induction in cats [19]. The present study revealed that the propofol Cps for another pharmacodynamic endpoint, the removal of ETT and SGAD, were similar. The impact of airway device type on a pharmacodynamic effect of propofol could depend on pharmacodynamic endpoint such as insertion and removal of the airway device.

The mean propofol Cps for response to airway device at extubation in the present study were higher than the mean predicted propofol Cps at extubation in the previous study, $2.2 \mu \mathrm{g} / \mathrm{m} l$ for the mixed-breed dogs and $1.6 \mu \mathrm{g} / \mathrm{m} l$ for the greyhounds, with premedication using opioid and acepromazine [2]. Additionally, the mean propofol Cp for response to airway device in the present study was higher than appropriate predicted propofol $\mathrm{Cp}$ for dental procedure $(2.5-4.7 \mu \mathrm{g} / \mathrm{m} l) \mathrm{with}$ ETT [2]. Previously, we examined propofol-fentanyl interaction in Beagles for apnea, response to mechanical ventilation, and response to endotracheal tube [8], which has clearly shown that coadministration of an opioid, fentanyl, reduces propofol requirements. The results of these previous and present studies suggest that a presence of opioid coadministration may reduce propofol requirements in ETT intubated dogs. Opioid coadministration might also be reduced propofol requirement to obtain apnea, tolerance to mechanical ventilation, and tolerance to airway device stimulation in dogs inserted SGAD.

In the current study, the $\mathrm{PaCO}_{2}$ at extubation was different between the ETT and SGAD groups. As change of cerebral blood flow would alter propofol kinetics in the brain [18], which would be caused by the cerebral blood flow autoregulation depending on carbon dioxide [12], the difference of the $\mathrm{PaCO}_{2}$ can influence the propofol $\mathrm{Cp}$ at extubation, theoretically. However, a previous study revealed that the difference of $\mathrm{PaCO}_{2}$ had no impact on halothane requirement in dogs [3]. The impact of $\mathrm{PaCO}_{2}$ difference might have been small in the present study.

One of the limitations in this study was that we investigated the propofol effect without any premedication. Although the premedication such as opioid is often administered in the practice anesthesia, we aimed to examine the propofol effect without other drugs because the influence of other drugs might be minimized in some cases. Further study is warranted to evaluate the effect of coadministration of other drugs.

In conclusion, the plasma propofol concentrations for apnea, response to mechanical ventilation, and response to airway device were similar between endotracheal tube and supraglottic airway device in Beagles. Without moderate to strong stimuli such as 
airway device insertion or painful stimulation during surgery, the type of airway device may have little impact on required propofol concentration during maintenance of anesthesia in dogs.

Further study is desired whether the type of airway device influences plasma propofol concentrations with coadministration of opioid.

ACKNOWLEDGMENT. This study was supported by departmental funding.

\section{REFERENCES}

1. Andreoni, V. and Lynne Hughes, J. M. 2009. Propofol and fentanyl infusions in dogs of various breeds undergoing surgery. Vet. Anaesth. Analg. 36: 523-531. [Medline] [CrossRef]

2. Beths, T., Glen, J. B., Reid, J., Monteiro, A. M. and Nolan, A. M. 2001. Evaluation and optimisation of a target-controlled infusion system for administering propofol to dogs as part of a total intravenous anaesthetic technique during dental surgery. Vet. Rec. 148: 198-203. [Medline] [CrossRef]

3. Eger, E. I. 2nd., Saidman, L. J. and Brandstater, B. 1965. Minimum alveolar anesthetic concentration: a standard of anesthetic potency. Anesthesiology 26: 756-763. [Medline] [CrossRef]

4. Haskins, S. C. 2015. Monitoring anesthetized patients. pp. 86-113. In: Veterinary Anesthesia and Analgesia, 5th ed. (Grimm, K. A., Lamont, L. A., Tranquilli, W. J., Greene, S. A. and Robertson, S. A. eds.), Wiley-Blackwell, Hoboken.

5. Hofmeister, E. H., Brainard, B. M., Sams, L. M., Allman, D. A. and Cruse, A. M. 2008. Evaluation of induction characteristics and hypnotic potency of isoflurane and sevoflurane in healthy dogs. Am. J. Vet. Res. 69: 451-456. [Medline] [CrossRef]

6. Hull, C. J. 1991. Pharmacokinetics for anaesthesia. Butterworth-Heinemann, Boston, U.S.A. pp. 143-223.

7. Iizuka, T., Kamata, M., Yanagawa, M. and Nishimura, R. 2013. Incidence of intraoperative hypotension during isoflurane-fentanyl and propofolfentanyl anaesthesia in dogs. Vet. J. 198: 289-291. [Medline] [CrossRef]

8. Iizuka, T., Masui, K., Miyabe-Nishiwaki, T., Kanazawa, H. and Nishimura, R. 2017. Propofol-fentanyl interaction in Beagles - Apnea, response to mechanical ventilation, endotracheal tube, and tetanic stimulation. Res. Vet. Sci. 115: 34-42. [Medline] [CrossRef]

9. Joshi, G. P., Inagaki, Y., White, P. F., Taylor-Kennedy, L., Wat, L. I., Gevirtz, C., McCraney, J. M. and McCulloch, D. A. 1997. Use of the laryngeal mask airway as an alternative to the tracheal tube during ambulatory anesthesia. Anesth. Analg. 85: 573-577. [Medline] [CrossRef]

10. Keegan, R. D. and Greene, S. A. 1993. Cardiovascular effects of a continuous two-hour propofol infusion in dogs. Comparison with isoflurane anesthesia. Vet. Surg. 22: 537-543. [Medline] [CrossRef]

11. Maeda, S., Tomoyasu, Y., Higuchi, H., Honda, Y., Ishii-Maruhama, M. and Miyawaki, T. 2016. Female patients require a higher propofol infusion rate for sedation. Anesth. Prog. 63: 67-70. [Medline] [CrossRef]

12. Meng, L. and Gelb, A. W. 2015. Regulation of cerebral autoregulation by carbon dioxide. Anesthesiology 122: 196-205. [Medline] [CrossRef]

13. Mosley, C. A. 2015. Anesthesia equipment. pp. 23-85. In: Veterinary Anesthesia and Analgesia, 5th ed. (Grimm, K. A., Lamont, L. A., Tranquilli, W. J., Greene, S. A. and Robertson, S. A. eds.), Wiley-Blackwell, Hoboken.

14. Mukhopadhyay, A., Tai, B. C., Remani, D., Phua, J., Cove, M. E. and Kowitlawakul, Y. 2017. Age related inverse dose relation of sedatives and analgesics in the intensive care unit. PLoS One 12: e185212. [Medline] [CrossRef]

15. Reed, F. and Iff, I. 2012. Use of a laryngeal mask airway in a brachycephalic dog with masticatory myositis and trismus. Can. Vet. J. 53: 287-290. [Medline]

16. Tobin, M. J. 1994. Mechanical ventilation. N. Engl. J. Med. 330: 1056-1061. [Medline] [CrossRef]

17. Tsai, Y. C., Wang, L. Y. and Yeh, L. S. 2007. Clinical comparison of recovery from total intravenous anesthesia with propofol and inhalation anesthesia with isoflurane in dogs. J. Vet. Med. Sci. 69: 1179-1182. [Medline] [CrossRef]

18. Upton, R. N., Ludbrook, G. L., Grant, C. and Doolette, D. J. 2000. The effect of altered cerebral blood flow on the cerebral kinetics of thiopental and propofol in sheep. Anesthesiology 93: 1085-1094. [Medline] [CrossRef]

19. van Oostrom, H., Krauss, M. W. and Sap, R. 2013. A comparison between the v-gel supraglottic airway device and the cuffed endotracheal tube for airway management in spontaneously breathing cats during isoflurane anaesthesia. Vet. Anaesth. Analg. 40: 265-271. [Medline] [CrossRef]

20. Wiederstein, I. and Moens, Y. P. 2008. Guidelines and criteria for the placement of laryngeal mask airways in dogs. Vet. Anaesth. Analg. 35: 374-382. [Medline] [CrossRef]

21. Wiederstein, I., Auer, U. and Moens, Y. 2006. Laryngeal mask airway insertion requires less propofol than endotracheal intubation in dogs. Vet. Anaesth. Analg. 33: 201-206. [Medline] [CrossRef] 